\title{
Origen y endurecimiento por dispersión de carbonitruros en un acero comercial microaleado al niobio y laminado en caliente ${ }^{(\bullet)}$
}

\author{
E. Valencia ${ }^{(*)}$ y H.J. Kestenbach ${ }^{(* *)}$ \\ Resumen Se presenta un estudio sobre el origen de los carbonitruros de niobio y su efecto en el endurecimiento \\ de un acero comercial microaleado y laminado en caliente. Para tal fin se utilizaron micrografías \\ ópticas y electrónicas; así como también ensayos mécanicos y modelos indirectos que permitieron \\ predecir el límite elástico teniendo en cuenta la composición del acero y sus características estructu- \\ rales. Los resultados mostraron una extensa precipitación en la austenita durante las últimas fases del \\ proceso de laminación siendo ésta responsable del principal aporte al endurecimiento por dispersión \\ en el material investigado. No hubo evidencias de precipitación en la ferrita por observaciones al \\ microscopio electrónico de transmisión y sólo una escasa precipitación interfásica fue detectada en \\ un $10 \%$ de las zonas observadas sin una apreciable contribución al endurecimiento del acero. \\ Palabras clave: Acero microaleado. Dispersión. Carbonitruros. Microscopía electrónica de \\ transmisión. Límite elástico. Acero laminado en caliente.

\section{Origin and dispersion strengthening of carbonitrides in a commercial hot strip microalloyed niobium steel}

\begin{abstract}
Throughout this work, a study on niobium carbonitrides formation and its hardening effect in a commercial hot strip microalloyed steel is presented. Optic and electron micrographs were obtained while mechanical tests and indirect models allow to predict samples yield strength, taking into account the steel composition and its structural characteristics. The results showed an extended precipitation on austenite boundary cells during the last thermomechanical processing stages, which probably achieved a considerable contribution to the hardening by dispersion in the material studied. Otherwise, no evidence of precipitation in ferrite by means of transmission electron microscopy (TEM) was observed. A poor interphase precipitation was detected in about 10 per cent of the total observed zones with no appreciated contribution to the steel hardness.
\end{abstract}

Keywords: Microalloyed steel. Dispersion. Carbonitrides precipitation. Transmission electron microscopy. Yield strength. Hot strip steel.

\section{INTRODUCCION}

Se ha aceptado que los mecanismos fundamentales que incrementan el límite elástico en los aceros microaleados son la reducción del tamaño de grano ferrítico y la fina precipitación de carburos o carbonitruros o de los elementos microaleados (1-4).

$(\bullet$ Trabajo recibido el día 16 de abril de 1998 y aceptado en su forma final el 14 de julio de 1998.

(*) Formalmente con la Universidad Central de las Villas (Cuba).

Dpto. de Enghenaria de Materiais. Universidade Federal de São Carlos. 13565-905 São Carlos, S.P., Brasil.

(**) Dpto. de Enghenaria de Materiais. Universidade Federal de São Carlos. 13565-905 São Carlos, SP, Brasil.
Constituye precisamente la precipitación y dispersión de las partículas de segunda fase la que más atención ha tenido en estos materiales, pues si bien la dependencia entre el tamaño de grano y el límite elástico obedecen a una relación del tipo Hall-Petch, el incremento del endurecimiento con la fina precipitación está condicionada a los tamaños de partículas, distribución y origen de su formación (5-7).

La precipitación de los carburos o carbonitruros puede producirse en la austenita durante la laminación debido a las limitadas solubilidades en esta fase, durante la transformación alotrópica $\gamma \rightarrow \alpha$ (precipitación interfásica) como consecuencia de una más baja solubilidad de los carburos o carbonitruros en la ferrita, unido a un fuerte efecto de nucleación heterogénea, y si aún el grado de 
sobresaturación es elevado, puede tener lugar la precipitación sobre las dislocaciones en el interior de los granos ferríticos (8).

En la literatura se establece que la precipitación de los carbonitruros en la austenita, en particular el carbonitruro de niobio, inducida adicionalmente por la deformación durante el laminado en caliente, no produce endurecimiento; disminuyendo por tanto la cantidad del elemento microaleante para la subsecuente precipitación en la ferrita (coherente o semicoherentemente), considerada como la única responsable de contribuir al aumento de la resistencia en los mismos (7, 9 y 10).

Durante los últimos decenios se utilizaron diferentes métodos, todos ellos indirectos, para cuantificar la contribución al endurecimiento de las partículas de segunda fase precipitadas en los aceros microaleados, dando como resultado un valor estimado de $100 \mathrm{MPa}$ para aquellos con pequeñas adiciones de niobio laminados en caliente (2), un incremento aproximado de $200 \mathrm{MPa}$ o más para estos mismos aceros, pero sin deformación (11), y una contribución hasta $600 \mathrm{MPa}$ para los aceros experimentales con elevados contenidos de niobio (12), vanadio (13) o titanio (14).

Se destaca que la gran mayoría de los resultados publicados en la bibliografía científica se refieren a la precipitación de los carburos o carbonitruros en condiciones de laboratorio, donde el tiempo disponible para la laminación en caliente es relativamente corto y, en consecuencia, la precipitación en la austenita será bastante menor, permaneciendo en solución quizás una mayor cantidad del elemento aleante para la precipitación en la ferrita.

El presente trabajo persigue una detallada investigación del origen de la precipitación de los carbonitruros de niobio y valorar su contribución al endurecimiento de un acero comercial microaleado al niobio laminado en caliente. Lo anterior permitirá realizar una revisión crítica del papel de la precipitación en la ferrita, pues a pesar de la importancia atribuida a tal proceso en el endurecimiento de estos materiales, aún no existe comprobación experimental convincente de la precipitación en la ferrita para aceros comerciales microaleados al niobio laminados en caliente.

\section{MATERIALES Y MÉTODOS}

$\mathrm{El}$ acero investigado fue suministrado por la Compañía Siderúrgica Paulista (COSIPA) en forma de chapas cuadradas $\left(400 \times 400 \mathrm{~mm}^{2}\right)$, las cuales se cortaron de la parte central de una bobina correspondiente a un acero comercial microaleado al niobio y laminado en caliente hasta un espesor de 10 mm. La composición química (\% peso) del material estudiado se muestra en la tabla I, donde los niveles
TABla I.- Composición química del acero comercial microaleado y laminado en caliente

TABLE I.- Chemical composition of the commercial hot strip microalloyed steel

\begin{tabular}{|c|c|c|c|c|c|c|}
\hline $\mathrm{C}$ & $\mathrm{Si}$ & $\mathrm{Mn}$ & $\mathrm{Al}$ & $\mathrm{Nb}$ & $\mathrm{N}$ & $\mathrm{Fe}$ \\
\hline 0,071 & 0,014 & 0,68 & 0,035 & 0,043 & 0,0096 & resto \\
\hline
\end{tabular}

del nitrógeno fueron los nominales para la tecnología utilizada en la fabricación del mismo.

Las condiciones del tratamiento termomecánico para la obtención de las chapas y el esquema del proceso de laminación en caliente se muestran en la figura 1. Las chapas fueron extraídas de la parte central de la bobina donde la velocidad de enfriamiento resultó ser la menor con respecto a las demás porciones de la misma.

Se obtuvieron muestras para la determinación de la estructura y tamaño de grano por microscopía óptica y microscopía electrónica de barrido (MEB) tomando secciones transversales a la dirección del laminado; también se prepararon probetas, siguiendo esta misma dirección, para los ensayos mecánicos de tracción y dureza Vickers. Una parte del material original fue sometido a un tratamiento térmico de normalización durante $35 \mathrm{~min}$ a $900{ }^{\circ} \mathrm{C}$, con la finalidad de detectar una posible precipitación coherente o semicoherente en la ferrita tomando como prueba experimental las variaciones de la dureza Vickers antes y después del tratamiento térmico.

Paralelamente, se colocó una serie de muestras del material suministrado en un régimen isotérmico a $650{ }^{\circ} \mathrm{C}$ durante diferentes intervalos de tiempo, los cuales fueron desde las 2 hasta las $167 \mathrm{~h}$, para determinar una posible precipitación en la ferrita posterior al ciclo térmico de enfriamiento de la bobina, a partir también de las posibles variaciones de la dureza Vickers con los distintos tiempos del tratamiento isotérmico.

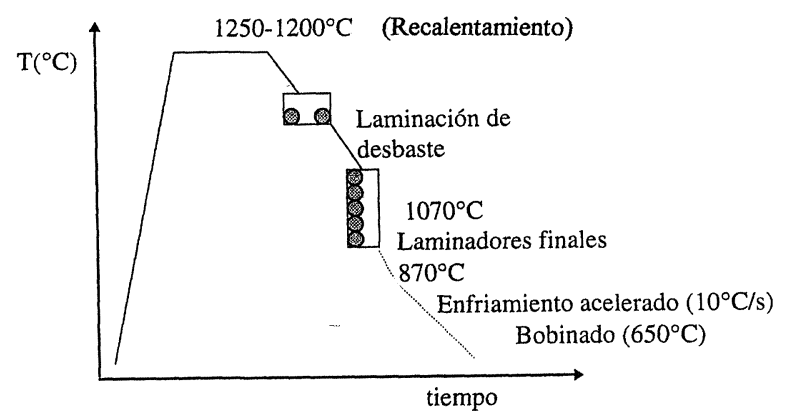

FIG. 1.- Proceso de laminación en caliente.

FIG. 1.-Industrial hot strip process. 
Se utilizó la microscopía electrónica de transmisión (MET) para caracterizar el origen de las partículas según sus diagramas de difracción, tamaños y distribución de los carbonitruros en las imágenes de campo claro y oscuro. Simultáneamente, se determinaron las fracciones volumétricas de precipitados según sus tamaños para más de 2.000 partículas en diferentes regiones de las láminas finas correspondientes a un volumen y área total analizadas de 1,3 $\mu \mathrm{m}^{3}$ y $11,5 \mu \mathrm{m}^{2}$, respectivamente. La determinación de las fracciones volumétricas por MET dependieron de la exactitud con que se calculó el espesor de las regiones observadas contando el número de franjas de espesor que aparecieron entre dos granos adyacentes cuando se tenía un haz fuertemente difractado para $w=0$ en uno de los granos,

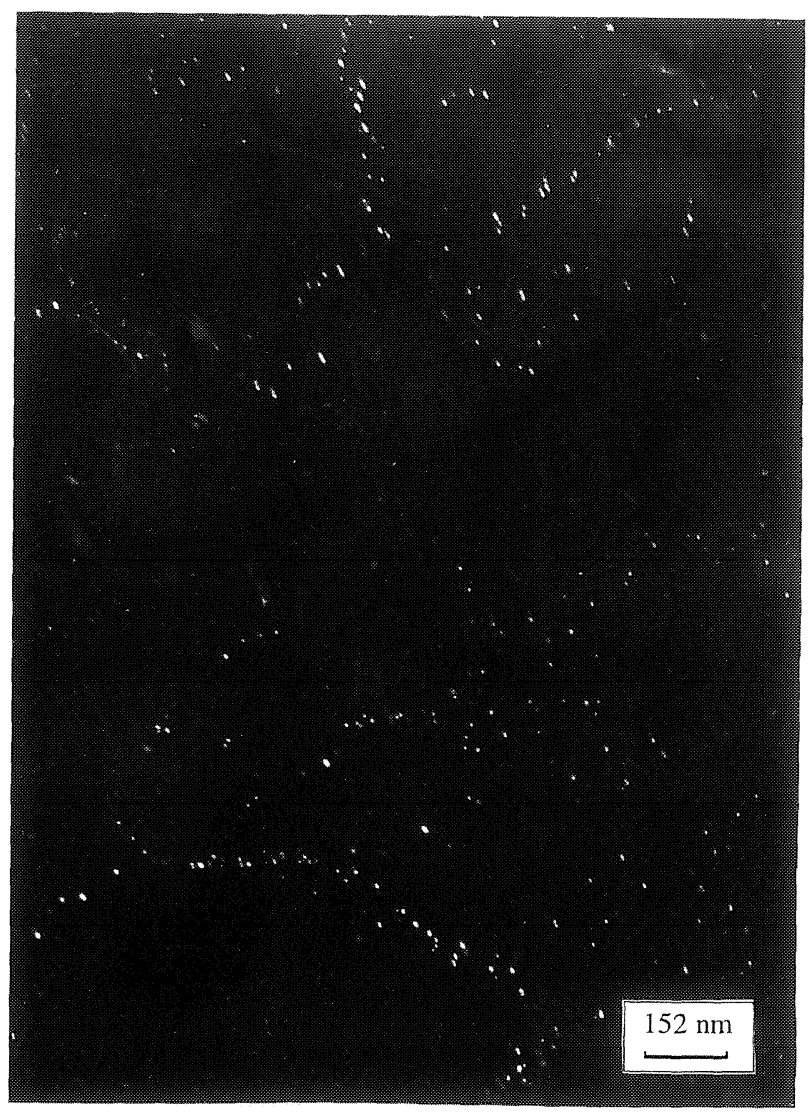

a) y sólo aparecían haces difractados muy débiles en el otro (15).

\section{RESULTADOS EXPERIMENTALES}

\subsection{Origen de la precipitación}

Con la finalidad de precisar en las características de la precipitación de los carbonitruros, se analizaron en el MET aproximadamente 20 diferentes regiones de las láminas finas. Las figuras $2 \mathrm{a}, 3 \mathrm{a}$ y $4 \mathrm{a}$ son un ejemplo de las zonas de precipitados más significativos tomadas en campo oscuro según las reflexiones indicadas por la posición de la apertura del objetivo en los diagramas de difracción de electrones correspondientes (Figs. 2b, 3b y 4b. En todas estas

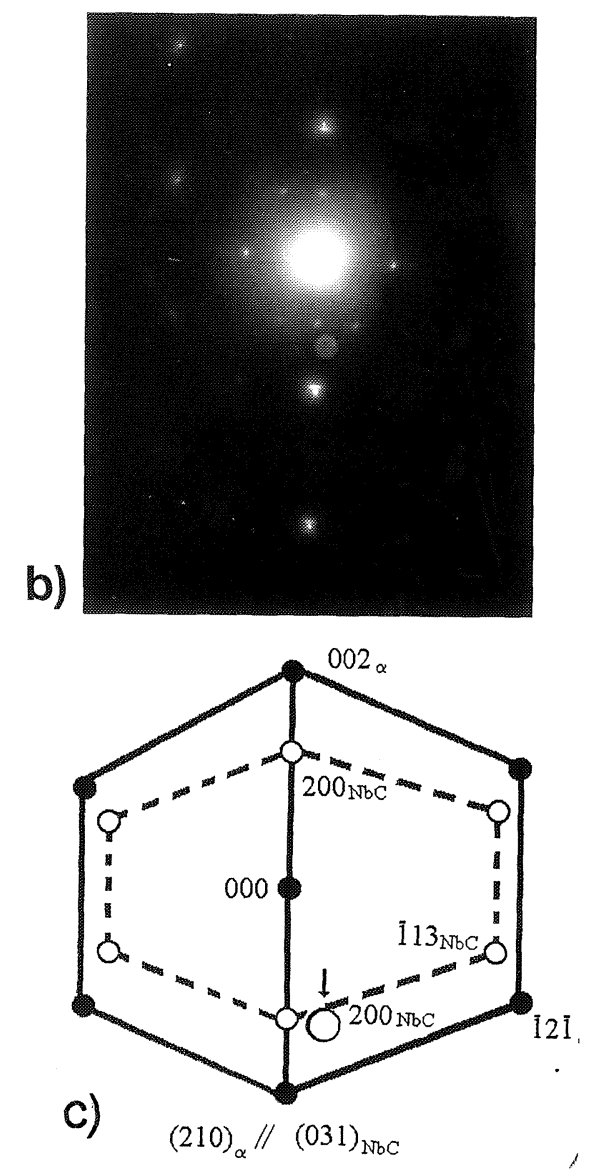

FIG. 2.- a) Precipitación del $\mathrm{Nb}(\mathrm{NC})$ en las fronteras de celdas austeníticas durante las etapas finales del tratamiento termomecánico. Campo oscuro. $\times 66.000$.

b) Patrón de difracción con la ubicación de la apertura del objetivo en la reflexión que mostró la precipitación en campo oscuro.

c) Patrón de difracción compuesto para la precipitación del carbonitruro de niobio en la ferrita mostrando la variante más cercana de B-N y la posición de la apertura del objetivo (ver flecha).

FIG. 2.- a) $\mathrm{Nb}(\mathrm{CN})$ precipitation at the austenitic boundary cells during the last stages of the thermomechanical treatment. Dark field image. $66.000 \times$

b) Diffraction pattern indicating objetive aperture at reflection position of dark field image (a).

c) Diffraction pattern of carbonitride precipitation in ferrite phase showing the nearest Baker-Nutting orientation relationship, indicating (by arrow) objetive aperture position. 
situaciones se destaca que las relaciones cristalográficas entre el precipitado y la fase $\alpha$ quedan fuera de las tres posibles orientaciones específicas para cuando el carbonitruro nuclea en la ferrita, conocidas como relaciones de orientación de Baker-Nutting (BN) (16), esquematizadas para las variantes más cercanas en las figuras $2 c, 3 c$ y $4 c$, donde se insertó la apertura del objetivo que iluminó las partículas en campo oscuro. De esta forma, las orientaciones aleatorias encontradas entre el precipitado y la matriz $\alpha$ sin corresponderse con las anteriores relaciones de orientación de B-N constituyen la evidencia fundamental de nucleación del carbonitruro en la fase austenítica. Además, esta precipitación registra la orientación de la austenita desde la cual precipitó el carbonitruro (16); así, teniendo en cuenta que la pre-

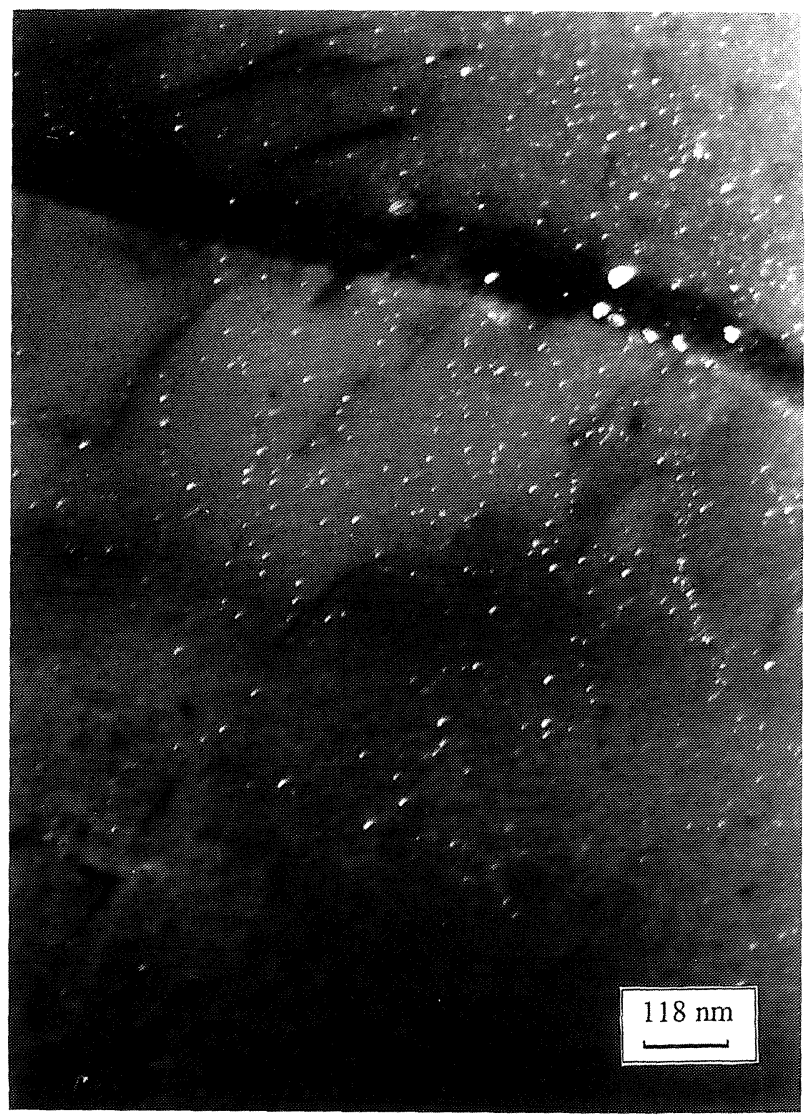

a) cipitación mayoritaria de partículas (diámetros menores de $10 \mathrm{~nm}$ ) fue iluminada con una simple reflexión, es un indicativo de que la nucleación de tales precipitados tuvo lugar en el acero en un estado en el que la austenita no cambia de orientación debido a los procesos de recristalización. Esto sugiere que la masiva precipitación se induce durante o después de las reducciones finales a las más bajas temperaturas, corroborado también por la distribución observada en las micrografías electrónicas donde los carbonitruros parecen localizarse en las subfronteras de celdas en una austenita deformada.

Del conjunto de observaciones solamente en dos regiones fue identificada la precipitación interfásica con su típica distribución en hileras equidistantes de precipitados muy finos. En la figura
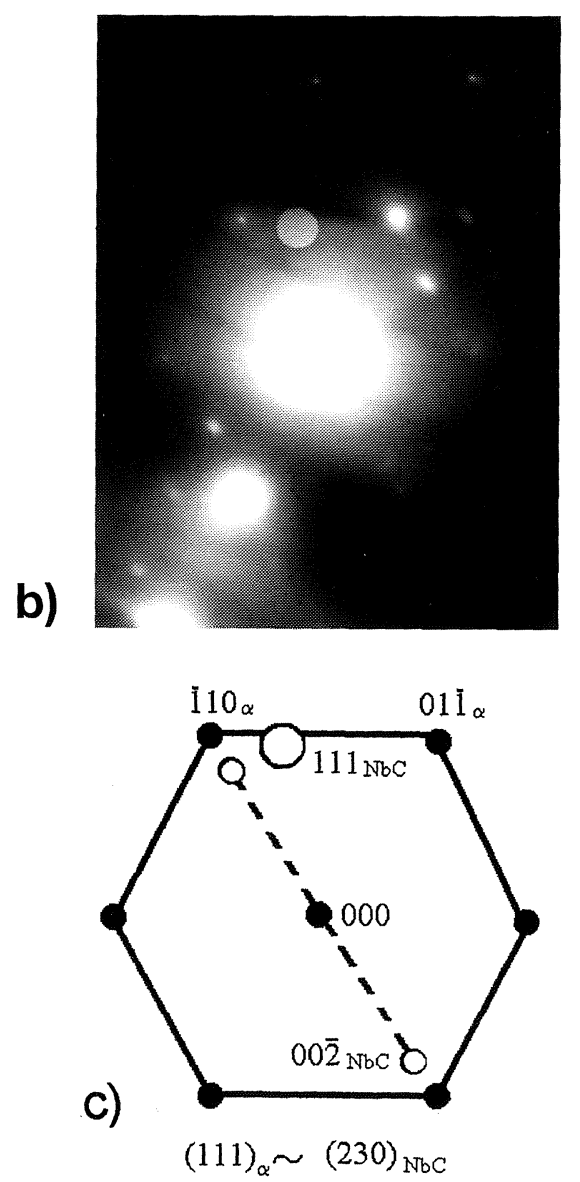

FIG. 3.- a) Precipitación del $\mathrm{Nb}(\mathrm{NC})$ en las fronteras de celdas austeníticas durante las etapas finales del tratamiento termomecánico. Campo oscuro. $\times 85.000$.

b) Patrón de difracción con la ubicación de la apertura del objetivo en la reflexión que mostró la precipitación en campo oscuro.

c) Patrón de difracción compuesto para la precipitación del carbonitruro de niobio en la ferrita mostrando la variante más cercana de B-N y la posición de la apertura del objetivo.

FiG. 3.- a) $\mathrm{Nb}(\mathrm{CN})$ precipitation at the austenitic boundary cells during the last stages of thet hermomechanical treatment. Dark field image. $85.000 \times$.

b) Diffraction pattern indicating objetive aperture at reflection position of dark field image (a).

c) Diffraction pattern of carbonitride precipitation in ferrite phase showing the nearest Baker-Nutting orientation relationship indicating objetive aperture position. 


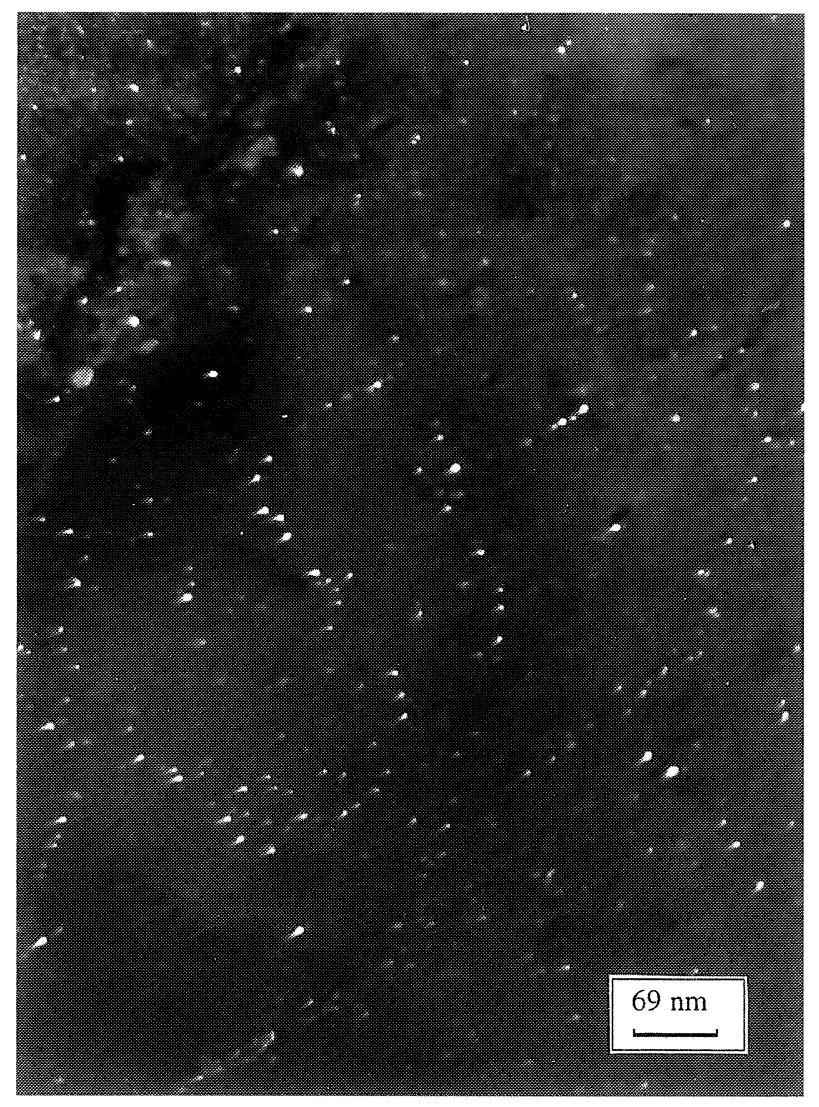

a)
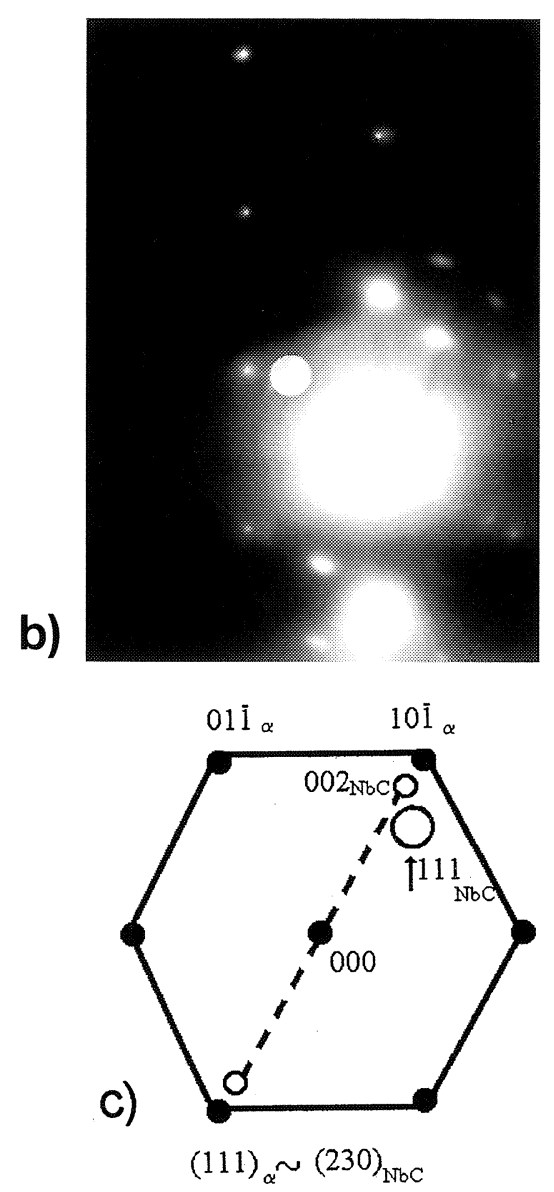

FIG. 4.- a) Precipitación del $\mathrm{Nb}(\mathrm{NC})$ en las fronteras de celdas austeníticas durante las etapas finales del tratamiento termomecánico. Campo oscuro. $\times 145.000$.

b) Patrón de difracción con la ubicación de la apertura del objetivo en la reflexión que mostró la precipitación en campo oscuro.

c) Patrón de difracción compuesto para la precipitación del carbonitruro de niobio en la ferrita mostrando la variante más cercana de B-N y la posición de la apertura del objetivo (ver flecha).

FIG. 4-a) $N b(C N)$ precipitation at the austenitic boundary cells during tha last stages of the thermomechanical treatment. Dark field image. $145.000 \times$.

b) Diffraction pattern indicating objetive aperture at reflection position of dark field image (a).

c) Diffraction pattern of carbonitride precipitation in ferrite phase showing the nearest Baker-Nutting orientation relationship indicating (by arrow) objetive aperture position.

5a se muestra la imagen en campo oscuro de una de las regiones iluminada con la reflexión 002 del $\mathrm{NbC}$ obedeciendo a una sola variante de B-N, $(111)_{\alpha \sim}(230)_{\mathrm{NbC}}$, mientras que la figura $5 b$ evidencia, en campo claro, la otra zona, satisfaciendo la variante $(011)_{\alpha} / /(001)_{\mathrm{NbC}}$ de B-N. Llama la atención que tal precipitación, como se observa en las micrografías anteriores, es escasa y poco uniforme. No se encontraron en el presente estudio precipitados de carbonitruros en las dislocaciones de la ferrita sobresaturada.

En los exámenes micrográficos al MEB y al microscopio óptico no se detectó la presencia de carbonitruros no disueltos a las altas temperaturas del tratamiento de recalentamiento $\left(1.200{ }^{\circ} \mathrm{C}\right)$, quizás por los bajos contenidos de carbono y niobio en el acero (Fig. 6), lo que concuerda con los resultados de Narita (17) para la solubilidad del $\mathrm{NbC}$ en la austenita; así, a $1.200{ }^{\circ} \mathrm{C}$ el acero con $0,07 \% \mathrm{C}$ puede solubilizar hasta un $0,16 \% \mathrm{Nb}$, contenido muy superior al $0,043 \% \mathrm{Nb}$ reportado para el material comercial microaleado que se investigó. Muestras de carbonitruros eutécticos no disueltos a las temperaturas de recalentamiento para otra familia de aceros comerciales microaleados se reportan en la bibliografía (18), donde pueden distinguirse perfectamente al microscopio óptico las partículas con $2 \mu \mathrm{m}$ de diámetro aproximadamente. 

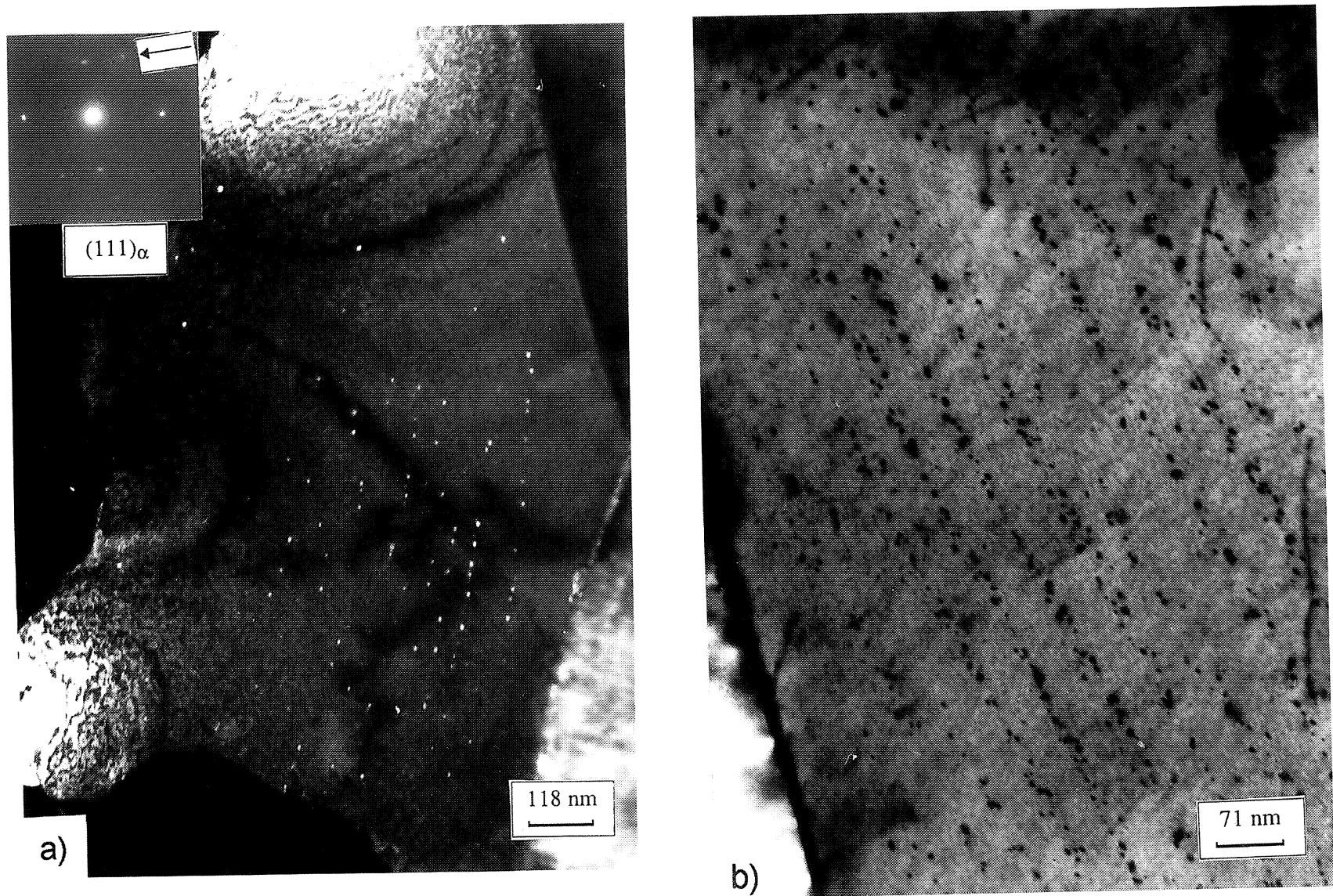

FIG. 5.- Precipitación interfásica de dos regiones diferentes.

a) Campo oscuro de la región I y patrón de difracción indicando la posición de la apertura del objetivo que mostró las hileras (ver flecha). $\times 85.000$.

b) Campo claro de la región II. $\times 140.000$.

FIG. 5.-- Interphase precipitation of two different zones.

a) Dark field image of zone I and diffraction pattern showing the Baker-Nutting relationship (by arrow).

b) Bright field inage of 2000 .

b) Bright field image of zone II. $140.000 \times$.

No fueron abundantes las regiones de fracciones volumétricas de precipitados, preferentemente alineados con diámetros superiores a los $10 \mathrm{~nm}$, que indicaron una precipitación en las fronteras de grano austenítico durante las primeras etapas de la laminación en caliente (18).

\subsection{Fracciones volumétricas precipitadas}

El cálculo de las fracciones volumétricas pro-medio y los tamaños de grano medio obtenidos experimentalmente son comparados con la fracción volumétrica máxima teórica que puede precipitar en el acero investigado, teniendo en cuenta que se forma un carbonitruro del tipo $\mathrm{Nb}(\mathrm{CN})$ con parámetro de red igual a $0,445 \mathrm{~nm}$ (Tabla II).

Se infiere que prácticamente el $43 \%$ de la fracción volumétrica teórica máxima precipita en la austenita durante las últimas etapas de la laminación en caliente y se discutirá posteriormente que ésta puede ser la que influye en el endurecimiento por dispersión en el acero microaleado investigado.

\subsection{Recocido isotérmico después del bobinado y el tratamiento de normalización}

Se ejecutó un recocido isotérmico a $650{ }^{\circ} \mathrm{C}$ durante intervalos de tiempo que oscilaron desde las 2 hasta las $167 \mathrm{~h}$ con el objețivo de verificar a través de los ensayos de dureza Vickers una subsecuente precipitación en la ferrita aún después del prolongado enfriamiento en la bobina (Fig.1). Los resultados del análisis de dureza frente al tiempo de tratamiento isotérmico (Fig. 7) no revelaron una variación apreciable de este parámetro mecánico, lo que permite suponer la ausencia de precipitación en esta 


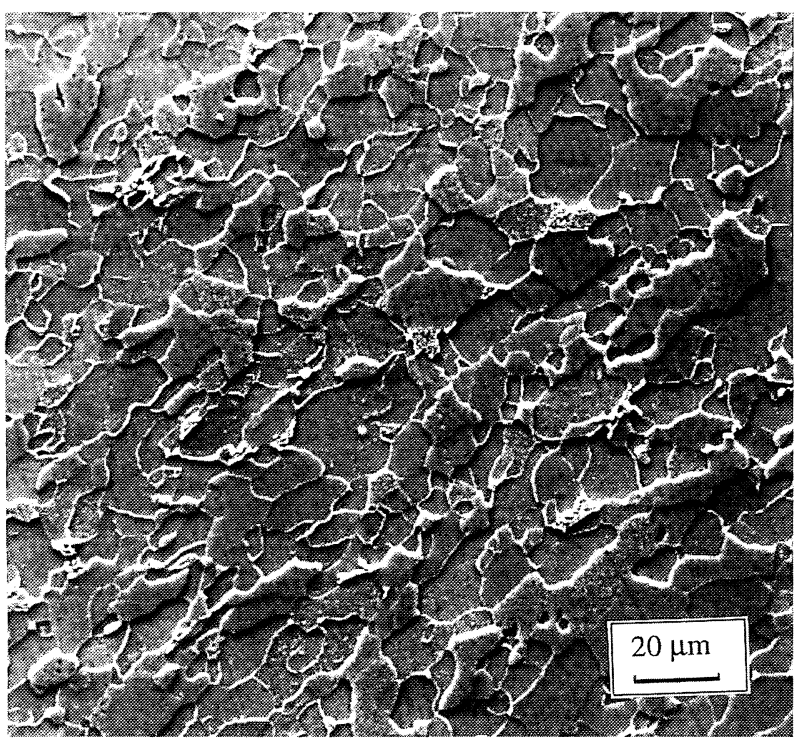

FIG. 6.- Ferrita poligonal del acero microaleado al niobio y laminado en caliente. Imagen al MEB. $\times 833$.

FIG. 6.- Polygonal ferrite grains in the hot strip $\mathrm{Nb}$-microalloyed steel. SEM image. $833 \times$.

fase de baja temperatura durante el propio proceso de bobinado. El tamaño medio de grano permaneció sin una apreciable alteración durante el tratamiento isotérmico, lo que no influyó en los resultados obtenidos.

La figura 8 muestra la micrografía en campo oscuro de áreas examinadas después del tratamiento de normalización a $900{ }^{\circ} \mathrm{C}$ durante 35 min en el acero microaleado al niobio. No se identificó un incremento de las fracciones volumétricas precipitadas ni una variación apreciable en el tamaño medio de partícula. Las distribuciones de precipitados continuaron reflejando la típica nucleación en las subfronteras de celdas en la fase austenítica, sin distinguirse un contraste de precipitados en las dis-

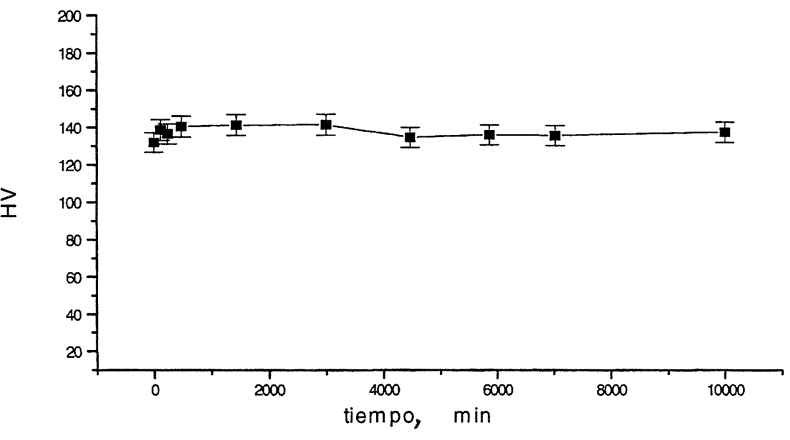

FIG. 7.- Dureza Vickers (HV) en función del tiempo de tratamiento isotérmico para el acero comercial microaleado.

FIG. 7.- Vickers hardness vs. corresponding isothermic treatment period for hot strip microalloyed steel.

locaciones ferríticas, como consecuencia de la pérdida de la coherencia de los finos carbonitruros que pudieron precipitar en esta fase durante su enfriamiento, lo que también se confirma por los valores de dureza del material antes del tratamiento de normalización, (130 HV) y después del mismo (132 HV) sin variar de forma apreciable los tamaños de grano.

\section{DISCUSIÓN}

\subsection{Precipitacón de carbonitruros}

Durante el proceso de fabricación y laminado en caliente de los aceros comerciales microaleados al niobio existen múltiples causas de la precipitación de los carbonitruros de niobio; por un lado, debido al descenso de la solubilidad del precipitado en las fases $\gamma$ y $\alpha$ al disminuir la temperatura durante el enfriamiento continuo (4), y por otro, debido a las

TABLA II.- Fracciones volumétricas y tamaños medios de partículas calculados para el conjunto de zonas observadas al MET

TABLE II.- Volumetric fractions an mean particle sizes calculated by transmission electron microscopy corresponding to the regions observed

\begin{tabular}{|c|c|c|c|c|c|}
\hline $\begin{array}{c}\text { Origen de } \\
\text { precipitados }\end{array}$ & $\begin{array}{c}\text { Número de } \\
\text { partículas } \\
\text { contadas }\end{array}$ & $\begin{array}{c}\text { Tamaño de } \\
\text { partículas, } \\
\mathrm{nm}\end{array}$ & $\begin{array}{c}\text { Fracciones } \\
\text { volumétricas } \\
\text { medidas } \\
(\mathrm{FT})\end{array}$ & $\begin{array}{c}\text { Fracción } \\
\text { teórica } \\
\text { máxima } \\
(\mathrm{FT})\end{array}$ & $\begin{array}{c}\text { FM/FT, } \\
\%\end{array}$ \\
\hline Austenita & 2.320 & $4-8$ & $1,12 \times 10^{-4}$ & $4,86 \times 10^{-4}$ & 23 \\
Austenita & 200 & $8-12$ & $9,8 \times 10^{-5}$ & $4,86 \times 10^{-4}$ & 20 \\
\hline
\end{tabular}




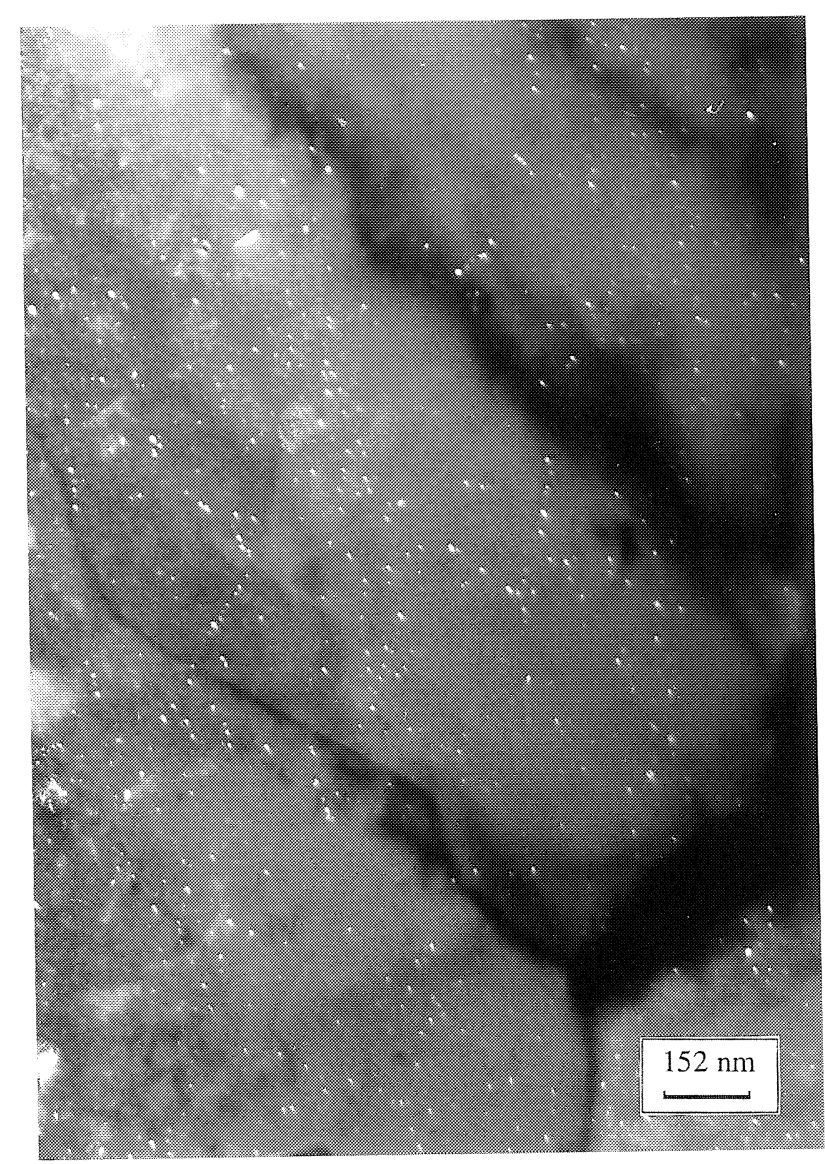

FIG. 8.- Precipitación del $\mathrm{Nb}(\mathrm{CN})$ en la austenita después de un tratamiento de normalización a $900{ }^{\circ} \mathrm{C}$ durante $35 \mathrm{~min}$. Campo oscuro. $\times 66.000$.

FIG. 8. - Nb(CN) precipitation in austenite after normalizing treatment at $900{ }^{\circ} \mathrm{C}$ temperature during 35 min. Dark field image. $66.000 \times$.

grandes deformaciones plásticas que sufre el material durante el proceso de laminación (19-20). De esta forma, las partículas de carbonitruros pueden precipitar preferentemente en las fronteras de grano austenítico, durante o después del tratamiento de laminación a alta temperatura donde simultáneamente estan ocurriendo los procesos de recristalización, o en las dislocaciones inducidas por la deformación durante la fase final del laminado, en una austenita no recristalizada. En estas últimas etapas, la distribución de los carbonitruros a la temperatura ambiente refleja las típicas subfronteras de celdas de la austenita deformada (21), aunque también los carbonitruros pueden escoger a las fronteras $\gamma-\gamma$ como lugares idóneos para la nucleación, identificadas en las micrografías por su distribución alineada, que abarcan dimensiones muy superiores a las ocupadas por las celdas (Fig. 9), las cuales son iluminadas en campo oscuro simultáneamente con aquellas que precipitaron en las subfronteras de celdas por

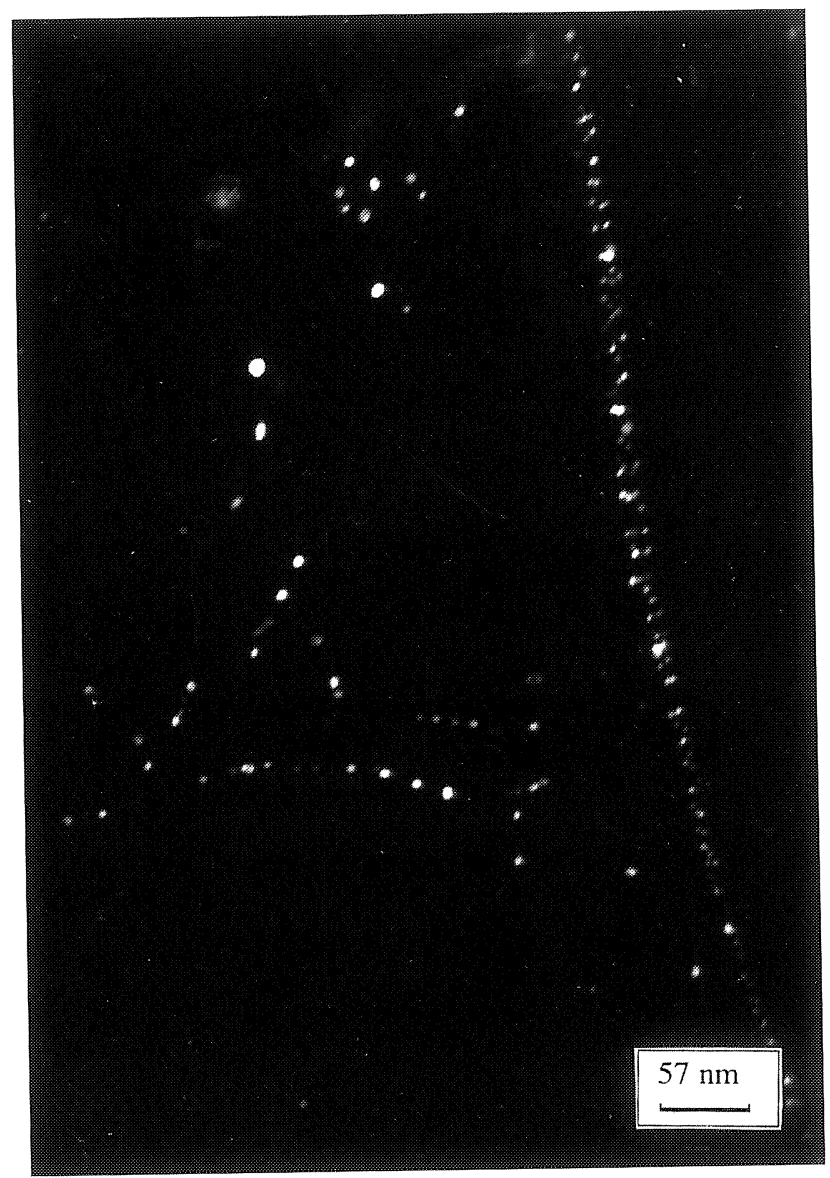

Fig. 9.- Precipitación del $\mathrm{Nb}(\mathrm{CN})$ en las fronteras $\gamma-\gamma$ y subfronteras de celdas austeníticas durante la etapa final del laminado. Campo oscuro. $\times 175.000$.

FIG. 9.- $N b(C N)$ precipitation in $\gamma-\gamma$ boundaries and austenitic sub-boundary cells during last stages of hot strip procedure. Dark field image. $175.000 \times$.

tener igual orientación con la última austenita que ya no recristaliza.

Generalmente, estos modos de precipitación en la austenita se distinguen por los tamaños y distribuciones de partículas. Así, cuando la nucleación es en las fronteras de grano a las más altas temperaturas su distribución es más alineada y sus tamaños superan los $20 \mathrm{~nm}$ como consecuecia de un incremento en las difusividades de los átomos a través de estas imperfecciones superficiales. Estas partículas mostrarán entonces un rango dado de orientaciones en la ferrita sin obedecer las relaciones de B-N, por lo que con una sola reflexión no se pueden iluminar todos los carbonitruros que nuclearon con diferentes orientaciones en la austenita debido a las subsecuentes deformaciones y procesos de recristalización. A las temperaturas finales del tratamiento termomecánico y por los altos grados de deformación, se induce una extensa precipitación 
de carbonitruros cuyos tamaños no superan los 10$12 \mathrm{~nm}$ distribuidos sobre las referidas fronteras de celdas en la austenita no recristalizada. El hecho de que con una sola reflexión sean iluminadas en campo oscuro una gran cantidad de ellas, demuestra la extensa precipitación durante estas fases de la deformación en caliente (Figs. 2-4).

Si no todo el elemento microaleante precipitó en la austenita, un substrato adecuado para la nucleación heterogénea lo constituyen las fronteras $\gamma-\alpha$ durante la transformación alotrópica de la austenita a ferrita, dando origen, cuando las condiciones de movilidad de las fronteras lo permitan, a un tipo de precipitación conocida como "precipitación interfásica" por su aparente ordenamiento, según hileras equiespaciadas de finos precipitados en las imágenes de campo claro y oscuro al MET (22 y 9). Este ordenamiento sólo será distinguido en las micrografías electrónicas cuando las capas que contienen las hileras de precipitados en la lámina fina sean paralelas al haz electrónico incidente (23); en otras situaciones será necesario complementar con los diagramas de difracción, pues este tipo de precipitación sólo obedece a una de las variantes de B-N (16). Las figuras 5 a y 5 b ejemplifican este tipo de precipitación encontrada solamente en dos de las veinte zonas estudiadas donde se destaca el gran espaciamiento entre las hileras de partículas precipitadas, que teniendo en cuenta los pequeños espesores de las láminas finas, posibilitan la observación de tal ordenamiento aun para situaciones donde las capas no sean exactamente paralelas al haz electrónico, lo que permite afirmar que la forma de este modo de precipitación no es abundante en el acero estudiado, y su contribución al endurecimiento debe ser poco significativo.

La precipitación desde la ferrita sobresaturada tiene lugar básicamente sobre las dislocaciones en esta fase de baja temperatura (24 y 8), aunque también pueden aparecer sobre las fronteras $\alpha-\alpha$. Este modo de precipitación al menos obedece a dos diferentes conjuntos de orientación de B-N (16), y esto lo distingue de la mencionada precipitación interfásica. En el presente estudio no se evidenció esta variante de precipitación quizás dado por los bajos contenidos de niobio en la matriz ferrítica después de la intensa precipitación en la austenita, lo que concuerda con una precipitación interfásica muy escasa, y la no variación de los parámetros mecánicos (dureza) después de un tratamiento de normalización a $900{ }^{\circ} \mathrm{C}$.

\subsection{Mecanismos de endurecimiento}

En consecuencia con los mecanismos básicos de endurecimiento en los aceros microaleados, muchos autores consideran que el incremento de la resisten- cia por precipitación de finos carbonitruros en la ferrita se favorece por el propio proceso industrial de laminado en caliente de chapas finas, dado por los pequeños tiempos entre pases de laminación y las altas temperaturas en los estadios finales del tratamiento termomecánico (25); sin embargo, aún no existen en la bibliografía trabajos convincentes que muestren tal precipitación en los aceros comerciales.

En este sentido, se hicieron predicciones del límite elástico a través de relaciones empíricas que solamente consideran el efecto del tamaño de grano y la composición química del acero (26):

$$
\begin{aligned}
\sigma_{\mathrm{e}}(\mathrm{MPa})= & 15,4[3,5+2,1(\% \mathrm{Mn})+5,4(\% \mathrm{Si})+ \\
& +23\left(\% \mathrm{~N}_{\mathrm{f}}\right)+1,13 d^{-1 / 2}
\end{aligned}
$$

siendo $(\% \mathrm{Mn}),(\% \mathrm{Si})$ y $(\% \mathrm{~N} f)$ los porcentajes en peso del manganeso, del silico y del nitrógeno libre, respectivamente en la matriz $\alpha$; y $d$, el diámetro medio del grano ferrítico en $\mathrm{mm}$.

'Teniendo en cuenta que en todo el rango de temperaturas, durante la laminación del acero microaleado al niobio, lo que se forma preferentemente desde el punto de vista cinético y termodinámico es un carbonitruro y no un carburo o nitruro simple de niobio (27), con estequiometría próxima al $\mathrm{Nb}(\mathrm{CN})$, la cantidad de nitrógeno necesario para agotar el niobio nominal de la aleación $(0,043 \%)$ se obtiene por la siguiente relación:

$$
\begin{aligned}
\left(\mathrm{M}_{\mathrm{Nb}} / \mathrm{M}_{\mathrm{N}}\right)(\% \mathrm{~N} / \% \mathrm{Nb}) & =1 \therefore(6,6371 / 0,043) \\
\% \mathrm{~N} & =1
\end{aligned}
$$

siendo $\mathrm{M}_{\mathrm{Nb}}$ y $\mathrm{M}_{\mathrm{N}}$ los pesos atómicos del niobio y nitrógeno respectivamente; así como también los porcentajes en peso de estos elementos en el acero. De esta manera se hace una estimación de la cantidad en tanto por ciento en peso del nitrógeno libre que permanece en el material, y que resultó ser el $0,0025 \%$.

La aplicación de las relaciones empíricas que consideran sólo el tamaño de grano y la composición química del acero mostró un endurecimiento de $252 \mathrm{MPa}$ para la ferrita poligonal con un tamaño de grano promedio de $10 \mu \mathrm{m}$ (Fig. 6), que comparado con los $310 \mathrm{MPa}$ obtenidos de los ensayos de resistencia, da una diferencia aproximada de 60 $\mathrm{MPa}$ asociada al endurecimiento por dispersión de carbonitruros.

El endurecimiento potencial por dispersión de una distribución dada de partículas en los aceros microaleados puede cuantificarse a través de la conocida relación de Orowan-Ashby modificada por Gladman (11): 


$$
\Delta \sigma[\mathrm{MPa}]=\frac{5,9 \sqrt{v_{\mathrm{f}}}}{\bar{x}} \ln \left(x / 2,5 \times 10^{-4}\right.
$$

donde el incremento a la resistencia debido a la dispersión de los precipitados $(\Delta \sigma)$ sólo depende de la longitud media de interceptación de las partículas en el plano de deslizamiento $\bar{x}$ de la fracción volumétrica precipitada $\left(v_{\mathrm{f}}\right)$. La relación entre $\bar{x}$ y el tamaño medio de las partículas medido directamente de las observaciones al MET en láminas finas se calcula según (28) por:

$$
\bar{x}=D(2 / 3)^{1 / 2}
$$

Para las fracciones volumétricas y tamaños medios de partículas registradas al MET en las diferentes zonas inspeccionadas (Tabla II), la aplicación de la ecuación modificada de Gladman dio como resultado un incremento en la resistencia de aproximadamente $65 \mathrm{MPa}$ como consecuencia de la fina dispersión de carbonitruros en la austenita, lo que parece concordar si se compara con la diferencia entre el valor de la resistencia experimental y el obtenido de las ecuaciones empíricas antes mencionadas. Se confirma así la poca o ninguna influencia en el endurecimiento de la escasa precipitación interfásica observada.

\section{CONCLUSIONES}

El análisis micrográfico al MET mostró que la precipitación de finos carbonitruros de niobio, durante los últimos estadios de la laminación en caliente para el acero comercial microaleado, era de un $40 \%$ respecto al contenido máximo que puede precipitar en el mismo con tamaños medios de partículas entre 4 y $8 \mathrm{~nm}$ para las subpoblaciones más significativas. La precipitación interfásica no fue muy observada, solamante se hizo en dos regiones del total de áreas analizadas por lo que no se estimó su aporte al endurecimiento del acero, lo que sí fue valorado para la gran dispersión de partículas más pequeñas nucleadas en la austenita.

Las predicciones realizadas por métodos indirectos haciendo uso de la ecuación de Gladman mostró un potencial de endurecimiento para las poblaciones de carbonitruros que precipitaron en las etapas finales de la laminación en caliente de aproximadamente $65 \mathrm{MPa}$, lo que resultó corresponderse con los niveles experimentales de resistencia después de considerar los efectos de tamaño de grano y endurecimiento por solución sólida. No hubo evidencias experimentales de precipitación sobre las dislocaciones en la ferrita.

\section{Agradecimientos}

Los autores agradecen a CNPq (Proceso 520700/953 ) y Fapesp (Procesos 96/5000-1 y 97/01324-0) por la financiación de la investigación. Se agradece a CNPq por las bolsas de investigación 300709/93-5 para H.-J.K. y 301080/96-8 para E.V.M.

\section{REFERENCIAS}

(1) Morrison, W.B. y Woodhead, J.H. J. Iron Steel Inst., 201, 1963: 43.

(2) Gray, J.M., Webster, D. y Woodhead, J.H. J. Iron Steel Inst., 203, 1965: 812.

(3) Morrison, W.B. J. Iron Steel Inst., 201, 1963: 317.

(4) Gray, J.M. Heat Treatment'73. The Metals Society. Londres, 1975: 19.

(5) Mangonon, P.L. y Heitman, W. Microalloying'75, Union Carbide. Nueva York, NY, 1977: 56.

(6) Gray, J.M. y DeARdo, A.J. HSLA Steels: Metallurgy and Applications (Beijing Conference), ASM, Metal Park, Ohio, 1986: 83.

(7) Tanino, M. y Aoki, K. Trans. Iron Steel Inst. Jpn, 8, 1968: 337.

(8) Honeycombe, R.W.K. Scand. J. Metall., 8, 1979: 21.

(9) Gray, J.M. y Yeo, R.B.G. Trans. ASM, 61, 1968: 255.

(10) Irvine, K.J., Gladman, T., OrR, J. y Pickering, F.B. $J$. Iron Steel Inst., 208, 1970: 717.

(11) Gladman, T., Dulieu, D. y McIvor, I.D. Microalloying'75, Union Carbide. Nueva York, NY, 1977: 32.

(12) Brito, R.M. y Kestenbach, J.H. J. Mater. Sci., 16, 1981: 1257.

(13) Batte, A.D. y Honeycombe, R.W.K. J. Iron Steel Inst., 211, 1973: 284.

(14) Freeman, S. y Honeycombe, R.W.K. Met. Sci., 11, 1977 : 59.

(15) Kestenbach, H.J. y Botta Filho, W.J. Microscopia Eletrônica: Transmissão e Varredura, São Paulo, SP, Associacão Brasileira de Metalurgia e Materiais, 1994: 80.

(16) Davenport, A.T., Brossard, L.C. y Miner, R. E. J. Met., 27, 1975: 21.

(17) Narita, K.S. Koyama. Kobe Steel Eng. Rept., 16, 1966: 179.

(18) Itman, A., Cardoso, K.R. y Kestenbach, H.J. Mater. Sci. Technol., 13, 1997: 49.

(19) Bon, Le, A. Rofes-Vernis, J. y Rossard, C. Mém. Sci. Rev. Met., 70, 1973: 577. 
(20) Watanabe, H., Smith, Y.E. y Pehlke, R.D. The Hot Deformation of Austenite, J.B. Ballance, ed., AIME, Nueva York, NY, 1977: 140.

(21) Kestenbach, H.J., Krause, W. and Silveira, T. L. Acta Metall., 26, 1978: 661.

(22) Davenport, A.T., Berry, F.G. y Honeycombe, R.W.K. Proc. Roy. Soc. Lond. A, 332, 1971: 191.

(23) Kestenbach, H.J. y Morales, E.V. Micros. Acta. Pendiente de publicación, 1998.

(24) Honeycombe, R.W.K. HSLA Steels: Metallurgy and Applications (Beijing Conference), ASM, Metal Park, Ohio, 1986: 243.
(25) Meyer, L., Straussburger, C. y Schneider, C. HSlA Steels: Metallurgy and Applications (Beijing Conference), ASM, Metal Park, Ohio, 1986: 29.

(26) Pickering, F.B. Physical Metallurgy and Desing of Steels, Applied Science, Londres, 1978: 63.

(27) Fuyu, S. y Wenxuan, C. HSla Steels: Processing, Properties and Applications, Ed. G. Tither and Z. Shouhua. The Minerals, Metals \& Materials Society, 1992: 43.

(28) Fullman, R.L. Trans. AIME., 197, 1953: 447. 